\title{
Implicações da análise univariada e multivariada na dissimilaridade de acessos de feijão comum
}

\author{
Implications of univariate and multivariate analyses on the dissimilarity of common bean \\ accessions
}

\author{
Sibila Grigolo ${ }^{1 *}$, Ana Carolina da Costa Lara Fioreze ${ }^{2}$, Sinara Denardi ${ }^{2}$ \& Jonathan Vacari ${ }^{3}$ \\ ${ }^{1}$ Universidade do Estado de Santa Catarina, Lages, SC, Brasil. 'Autor para correspondência: sibilagrigolo@gmail.com. \\ ${ }^{2}$ Universidade Federal de Santa Catarina, Curitibanos, SC, Brasil. \\ ${ }^{3}$ Monsanto, Não-Me-Toque, RS, Brasil.
}

Submissão: 16/03/2017 / Aceite: 13/06/2018

\begin{abstract}
RESUMO
As análises univariadas e multivariadas vem sendo rotineiramente utilizadas para a discriminação de genótipos em programas de melhoramento genético, muito embora nem sempre é realizada a análise da relação existente entre elas. Com isso, o objetivo deste trabalho foi relacionar a análise univariada e multivariada na dissimilaridade entre acessos de feijão comum, com base nas características dias para emergência, altura da planta, altura de inserção da primeira vagem, dias para colheita, estande final, número de vagens por planta, comprimento da vagem, massa de 100 sementes, rendimento de grãos, comprimento, largura e espessura da semente. Os dados foram submetidos à análise de variância univariada, com agrupamento de médias pelo teste de Scott-Knott e, à análise multivariada, para estimar a divergência genética com base na distância generalizada de Mahalanobis, agrupando os acessos pelo método de Tocher. Foi estimada a importância relativa dos caracteres pelo método de SINGH (1981) e realizado o diagnóstico de multicolinearidade. Houve diferença significativa para todas as características avaliadas, demonstrando a variabilidade existente entre os acessos, sendo que a maior variabilidade encontrada referiu-se aos caracteres da semente. Foi possível relacionar as análises univariada e multivariada, já que houve uma relação entre os grupos gerados pelo Scott-Knott e a porcentagem da contribuição relativa dos caracteres avaliadas. Já o agrupamento obtido na análise univariada para a característica que mais contribuiu para divergência entre os acessos não se mostrou compatível com o agrupamento gerado pelo método de Tocher. A utilização das análises em conjunto pode auxiliar o melhorista na tomada de decisão, escolhendo genótipos superiores e que apresentam ampla divergência genética principalmente para as características de maior interesse.
\end{abstract}

PALAVRAS-CHAVE: Phaseolus vulgaris L., melhoramento genético, caracterização de germoplasma, análise de agrupamento.

\begin{abstract}
Univariate and multivariate analyses have been routinely used to discriminate genotypes in breeding programs, but their relationship is not always considered. The objective of this study was to relate univariate and multivariate analyses on the dissimilarity among common bean accessions based on characteristics such as days until emergence, plant height, first pod insertion height, harvest days, final stand, number of pods per plant, pod length, 100-grain weight, grain yield and seed length, width and thickness. Data were submitted to univariate analysis of variance, with a comparison of means by the Scott-Knott test, and multivariate analysis to estimate the genetic divergence based on the generalized Mahalanobis distance, grouping the accesses through Tocher's method. The relative importance of the characters was also estimated by Singh's method, performing the multicollinearity diagnosis. There was a significant difference for all the evaluated characteristics, showing the existence of variability between the accesses. The greater variability found was related to seed characteristics. It was possible to relate univariate and multivariate analyses, since there was a relationship between the groups generated by Scott-Knott's test and the percentage of the relative contribution of the evaluated characters. However, the clustering obtained in the univariate analysis for the characteristic that contributed the most to the divergence between the accessions was not compatible with the cluster generated by Tocher's method. The coupled use of these analyses can help breeders to decide, choosing superior genotypes and that present wide genetic divergence, mainly for the characteristics of greater interest.
\end{abstract}


KEYWORDS: Phaseolus vulgaris L., genetic improvement, germoplasm characterization, cluster analysis.

\section{INTRODUÇÃO}

A espécie Phaseolus vulgaris L. é considerada não cêntrica, tendo dois centros primários de domesticação originando dois pools gênicos, o andino e o mesoamericano. Aliado a isso, o seu cultivo ocorre em diferentes regiões do Brasil, tendo grande potencial de adaptação em diferentes altitudes, podendo ser cultivado em monocultivo, consorciado ou em rotação com outras espécies (KRAUSE et al. 2012). Esses fatores contribuem significativamente para elevada variabilidade genética existente na cultura (TSUTSUMl et al. 2015).

A conservação e manutenção da variabilidade genética fora dos centros de origem se dá via bancos de germoplasma. Esses são essenciais para ancorar programas de melhoramento, disponibilizando genótipos tanto cultivados quanto silvestres, constituindo fonte de genes de determinadas características que, muitas vezes, podem resultar na melhoria de cultivares comerciais (RANGEL et al. 2013). Outro fator relevante remete-se a caracterização dos acessos do banco de germoplasma. Estudos com esse objetivo, fornecem subsídios para mensurar a dissimilaridade existente entre genótipos de acordo com parâmetros mensurados. A identificação de genótipos contrastantes permite a exploração da heterose ou vigor híbrido quando realizada a hibridação entre eles. Tal fato, possibilita maior efeito heterótico e maior heterozigose na progênie tendo maior probabilidade de selecionar genótipos superiores nas gerações segregantes e obtenção de novas cultivares superiores (CRUZ et al. 1994). Entretanto, a falta de informação dos acessos disponíveis é o fator mais limitante da baixa exploração pelos melhoristas (VALLS 2007, LIMA et al. 2012).

A utilização de métodos estatísticos facilita a análise dos dados. Tais métodos podem ser agrupados em dois conjuntos: estatística univariada e estatística multivariada. A principal diferença entre essas análises refere-se a consideração dos conjuntos de variáveis. A análise univariada é a maneira mais fácil e prática para obter ganhos com uma única característica por vez. Utiliza-se de procedimentos adequados para inferir individualmente sobre variáveis respostas desconsiderando qualquer estrutura de relação importante, ou seja, não contempla a covariância (COIMBRA et al. 2007). As técnicas multivariadas identificam grupos similares e dissimilares através de um conjunto de informações, as quais são analisadas simultaneamente (DALLASTRA et al. 2014). Esta constitui-se de medidas que representam mais de uma variável resposta amostral, e é considerado o inter-relacionamento mútuo do conjunto de características (SILVA \& MACHADO 2001). COELHO et al. (2007) relatam que quando comparada as duas análises alguns caracteres não foram significativos na univariada, podendo alterar a importância relativa de determinadas características.

Quando efetuada a análise de variância com aplicação do teste $\mathrm{F}$ de Snedecor (univariada) e este indica efeito diferencial, rejeitando a hipótese de nulidade, as conclusões são muito gerais sobre o comportamento dos tratamentos. Comparações múltiplas entre as médias possibilitam a discriminação entre tratamentos, obtendo resposta mais minuciosa (BANZATTO \& KRONKA 2006). O teste proposto por SCOTT \& KNOTT (1974) é um dos testes mais utilizados no melhoramento de plantas. Segundo RAMALHO et al. (2005), o teste utiliza a razão de verossimilhança para testar a significância entre tratamentos, visando separar as médias desses em grupos distintos, minimizando a variação dentro dos grupos e maximizando entre os grupos. Entre algumas características vantajosas, apresenta um elevado poder de teste e elimina a ambiguidade nos resultados tendo maior facilidade na interpretação (BORGES \& FERREIRA 2003).

Para SILVA \& MACHADO (2001), para cada método univariado há um análogo método multivariado. Contudo, alguns são específicos da estatística multivariada como exemplo, os métodos aglomerativos. Esses reúnem por algum critério de classificação, genótipos em determinados grupos de tal forma que exista homogeneidade dentro de cada grupo e heterogeneidade entre eles. Esses métodos diferem dos demais por dependerem de medidas de dissimilaridade estimadas previamente, como a distância generalizada de Mahalanobis $\left(D^{2}\right)$ e, posteriormente, é realizada a formação de grupos. No melhoramento genético comumente emprega-se o método de Tocher citado por RAO (1952). O método utiliza-se de uma matriz de dissimilaridade, sobre a qual identifica-se o par de genótipos mais similar, os quais formarão o grupo inicial e em sequência a inclusão de novos genótipos no grupo se dará pelo mesmo critério (CRUZ et al. 2012).

Muito embora existam diferentes métodos na análise univariada e multivariada, a relação entre elas é um tema pouco abordado, sendo bastante comum o uso de ambas em publicações científicas, mas sem uma discussão de sua relação. Com isso, o objetivo do presente trabalho, é relacionar a análise univariada e multivariada na dissimilaridade entre acessos de feijão comum. 


\section{MATERIAL E MÉTODOS}

O estudo foi conduzido na safra de 2014/2015 na Fazenda Experimental da Universidade Federal de Santa Catarina, no município de Curitibanos, SC $\left(27^{\circ} 16^{\prime}\right.$ S e $\left.50^{\circ} 30^{\prime} \mathrm{W}\right)$, com altitude de 987 metros. O solo da área é classificado como Cambissolo Háplico e apresenta clima do tipo Cfb (Clima subtropical úmido mesotérmico) com temperatura média entre 15 e $25^{\circ} \mathrm{C}$, com uma precipitação média anual de $1500 \mathrm{~mm}$.

Os dados obtidos foram formados pela avaliação de 20 acessos de feijão provenientes do Banco Ativo de Germoplasma da Embrapa Arroz e Feijão (Tabela 1). A unidade experimental consistiu de uma linha de um metro, espaçada em 0,50 metros, com densidade de oito sementes por metro linear. $O$ delineamento de blocos casualizados foi utilizado com três repetições. Devido à pequena quantidade de sementes disponíveis, optou-se por priorizar as repetições, atendendo também o princípio básico do controle local amenizando a heterogeneidade existente na área. CATAPATTI et al. (2008) observaram que pequenas amostras podem ser adotadas sem alteração da precisão experimental, já quanto maior o número de repetições, houve aumento de caracteres significativos, possibilitando a detecção de pequenas diferenças entre os genótipos avaliados. CARGNELUTTI FILHO et al. (2008) ressaltam que aumentar o número de repetições e diminuir o tamanho de amostra contribui para a melhoria da precisão experimental, pois o aumento do número de repetições é mais significativo para reduzir a estimativa da variância média estimada. Com base no experimento desenvolvido por RIBEIRO et al. (2001) para a cultura do feijão, a não utilização de bordaduras nas unidades experimentais, não reduziu a precisão na comparação de genótipos. Para tanto, aliado à pouca disponibilidade de sementes, não houve a utilização de linhas de bordadura nas unidades experimentais.

Tabela 1. Acessos do Banco Ativo de Germoplasma da Embrapa Arroz e Feijão.

Table 1. Accesses of the Embrapa Germplasm Active Bank of Rice and Beans.

\begin{tabular}{ccccc}
\hline Numeração & No BAG & Identificação & Cor do grão & Tamanho do grão1 \\
\hline 1 & BGF12863 & Cavalo & Manteigão & Médio \\
2 & BGF16037 & Rajado & Manteigão & Médio \\
3 & BGF12816 & 60 dias & Preto & Médio \\
4 & BGF16004 & Azulão & Preto & Pequeno \\
5 & BGF16057 & Italiano & Vermelho & Médio \\
6 & BGF12871 & Enxofre & Mulatinho & Pequeno \\
7 & BGF12881 & Preto de Copa & Preto & Pequeno \\
8 & BGF12791 & Mourinho & Outros & Pequeno \\
9 & BGF12905 & Vermelho Graúdo & Vermelho & Médio \\
10 & BGF12801 & Preto & Preto & Pequeno \\
11 & BGF16020 & Crioulo Miúdo & Preto & Pequeno \\
12 & BGF12810 & Vermelho & Vermelho & Médio \\
13 & BGF12780 & Manteiguinha & Preto & Pequeno \\
14 & BGF12934 & Preto Brilhante & Preto & Pequeno \\
15 & BGF12770 & Preto & Preto & Pequeno \\
16 & BGF12895 & Feijão de Vagem Azul & Preto & Pequeno \\
17 & BGF12723 & Amarelo & Roxo & Grande \\
18 & BGF16046 & Crioulo Rainha & Rajado & Médio \\
19 & BGF12753 & Bico de Ouro & Mulatinho & Médio \\
20 & BGF16024 & Barriga Verde & Preto & Pequeno \\
\hline
\end{tabular}

${ }^{1}$ Classificação baseada no Documento 184 - Descritores mínimos indicados para caracterizar cultivares/variedades de feijão comum (Phaseolus vulgaris L.) da Embrapa Arroz e Feijão. SILVA (2005).

A área onde o experimento foi implantado vem sendo cultivada em sistema de plantio direto, sendo que a cultura antecessora no inverno foi a canola. A adubação foi realizada com base nas recomendações técnicas para a cultura após realização da análise do solo (SOCIEDADE BRASILEIRA DE CIÊNCIA DO SOLO 2004). A adubação de cobertura foi realizada no estádio R5 na forma de ureia. Todos os tratos culturais foram efetuados de maneira manual e não houve aplicação de nenhum defensivo agrícola. 
Características morfoagronômicas foram utilizadas para caracterizar os genótipos. Doze caracteres obtidos ao longo do ciclo e após a colheita foram mensurados, sendo eles durante o ciclo: dias para a emergência (DPE), número de dias da semeadura até emergência da plântula; altura da planta (AT), medida em $\mathrm{cm}$ do nível do solo até a extremidade da planta; altura de inserção da primeira vagem (Al), medida em $\mathrm{cm}$ do nível do solo até a inserção do primeiro legume; dias para a colheita (DC), número de dias da semeadura até a maturação fisiológica da vagem; estande final (EF), número de plantas obtidas na colheita. Após a colheita foram contabilizadas as características: número de vagens por planta (NVP); comprimento da vagem (CV), medida longitudinal em $\mathrm{cm}$ de uma extremidade a outra da vagem; massa de 100 sementes (M100), média do peso de quatro amostras de 100 grãos em gramas; rendimento de grãos (REND), em kg $\mathrm{ha}^{-1}$; tamanho das sementes: comprimento da semente (CS), medida paralelamente ao hilo em $\mathrm{mm}$; largura da semente (LS), medida desde o hilo até ao lado oposto em $\mathrm{mm}$; e, espessura da semente (ES), em $\mathrm{mm}$. Para as variáveis DPE, AT, Al e NVP foram avaliadas todas as plantas existentes nas unidades experimentais de acordo com cada genótipo. Para a variável CV, foram mensuradas 10 vagens selecionadas aleatoriamente de cada unidade experimental. As variáveis referentes ao tamanho das sementes foram avaliadas em 50 sementes selecionadas aleatoriamente por unidade experimental.

Os dados foram submetidos à análise de variância univariada pelo teste $F$, seguidos de comparação de médias pelo teste de Scott-Knott, a $5 \%$ de probabilidade de erro. Posteriormente, os dados foram submetidos a análise multivariada, e com base na matriz de distância generalizada de Mahalanobis $\left(D^{2}\right)$ foi empregado o agrupamento pelo método de otimização de Tocher (RAO 1952). Antes da aplicação das técnicas multivariadas de agrupamento, procedeu-se o diagnóstico de multicolinearidade na matriz de correlação residual, a fim de descartar características que poderiam ser redundantes nas análises. Também foi mensurada a importância relativa dos caracteres pelo método de SINGH (1981). As análises estatísticas foram realizadas por meio do programa computacional Genes (CRUZ 2001).

\section{RESULTADOS E DISCUSSÃO}

Os resultados da análise de variância univariada e o agrupamento pelo teste de comparação de médias de Scott-Knott são apresentados nas Tabelas 2 e 3. Diferenças significativas foram encontradas entre os acessos de feijão comum em todos os caracteres avaliados, indicando a existência de variabilidade entre os acessos, sendo interessante do ponto de vista da utilização dos acessos em programas de melhoramento genético. Houve maior número de grupos para o aspecto morfológico da semente, em que a característica comprimento da semente dividiu-se em oito grupos, seguido da largura e espessura das sementes, formando cinco grupos cada. Segundo SILVA (2005), as características externas da semente do feijão possuem ampla variabilidade, sendo fatores que são altamente utilizados para diferenciar e classificar feijões em grupo ou tipos comerciais distintos.

Para a variável comprimento da semente, houve variação de 7,6 a 14,4 mm (Tabela 3). O acesso BGF 12723 ficou em um grupo isolado, apresentando a maior média (14,4 mm). Em contrapartida, o acesso BGF 16020 apresentou comprimento de semente de 7,6 mm, ou seja, o BGF 12723 obteve quase o dobro do tamanho para essa característica entre os grupos mais divergentes. $O$ intervalo médio que mais agrupou para essa variável foi de 9,0 a $9,6 \mathrm{~mm}$, em que $30 \%$ dos acessos estão alocados nesse grupo. Em relação à largura da semente (Tabela 3), a maior proporção dos acessos (40\%), ficou em intervalo médio de 6,0 a 6,2 $\mathrm{mm}$ de largura. Os grupos mais divergentes foram compostos por dois acessos cada. Os acessos BGF 12723 e BGF 12810 compuseram o grupo com maior média, 7,7 mm e 7,6 mm respectivamente, enquanto os acessos BGF 12801 e 12770 formaram o grupo com as menores médias de 5,8 mm e 5,7 mm, respectivamente. Para a variável espessura da semente (Tabela 3), os grupos mais contrastantes foram formados por três acessos (BGF 12816, 12905 e 12810) formando a extremidade de maior média com 5,7 $\mathrm{mm}$, e dois acessos (BGF 12895 e 12881) compondo a extremidade oposta, com média de 3,45 mm. Os valores obtidos dessas três características resultam no tamanho e forma da semente, que segundo CHIORATO (2004) são descritores morfológicos que contribuem para identificar as raças existentes em cada pool gênico.

Para as outras variáveis, a aplicação do teste de SCOTT \& KNOTT (1974) possibilitou a classificação dos acessos de feijão, de maneira decrescente, em quatro grupos para as variáveis dias para colheita e comprimento da vagem, três grupos para a variável dias para emergência e dois grupos para os caracteres altura de inserção da primeira vagem, estande final, número de vagem por planta, rendimento de grãos e massa de 100 grãos. A característica dias para colheita, mesmo não sendo um descritor mínimo para caracterização de cultivares de feijão (SILVA 2005), é uma característica importante de ser mensurada indicando se a cultivar tem ciclo precoce ou tardio. A maior parte dos acessos (80\%) nesse experimento, 
apresentou ciclo normal (85-95 dias) e apenas quatro foram classificados como ciclo semiprecoce (75-85 dias), característica esta, que pode ser considerada em hibridações quando se almeja obter cultivares que se encaixem bem em épocas de cultivo de uma determinada região. Outra característica válida refere-se à altura de inserção da primeira vagem, devido ao interesse em fazer uso da colheita mecanizada para a cultura do feijão. A maior parte das cultivares existentes no Brasil apresentam a altura de inserção da primeira vagem abaixo do alcance das lâminas de corte das ceifadoras, geralmente entre 5 e $10 \mathrm{~cm}$ (SILVA \& FONSECA 1996, SALGADO et al. 2011). Nesse sentido, é interessante observar o grupo formado pelas maiores médias. Tal grupo alocou $40 \%$ dos genótipos obtendo um valor médio de $16,5 \mathrm{~cm}$ para a inserção da primeira vagem. SILVEIRA (1991), citado por JADOSKI et al. (2000), aponta que vagens com altura mínima de $15 \mathrm{~cm}$ acima do solo já são viáveis para utilização da colheita mecanizada, assim esses acessos tornam-se pertinentes para utilização em hibridações onde se deseja incrementar a altura de inserção da primeira vagem. Além disso, quanto mais alto estiverem inseridas as vagens, menor a possibilidade de perda devido a redução do contato delas com a umidade do solo reduzindo as chances de ocorrer doenças fúngicas (GONÇALVES et al. 2014), fato este de grande relevância no cultivo do feijoeiro, onde há grande prejuízo na produtividade de grãos em virtude de tais doenças.

Tabela 2. Análise de variância das características, distribuição dos acessos de feijão comum em diferentes grupos de dissimilaridade estabelecidos pelo agrupamento de Tocher e média das características avaliadas para os 20 acessos de feijão.

Table 2. Analysis of variance of the characteristics, distribution of common bean accessions in different dissimilarity groups established by Tocher grouping and mean values of the evaluated characteristics for the 20 bean accessions.

\begin{tabular}{|c|c|c|c|c|c|c|c|}
\hline${ }^{1} \mathrm{FV}$ & Tocher & ${ }^{3} \mathrm{DPE}$ & ${ }^{3} \mathrm{AT}$ & ${ }^{3} \mathrm{Al}$ & ${ }^{3} \mathrm{DC}$ & ${ }^{3} \mathrm{EF}$ & ${ }^{3} \mathrm{NVP}$ \\
\hline Trat & -------- & $30,86^{*}$ & 85,00 & 39,93 & 70,26 & 8,11 & 153,55 \\
\hline Erro & ------- & 5,29 & 33,36 & 14,41 & 6,81 & 2,60 & 52,46 \\
\hline BGF12791 & 1 & $7,0 \mathrm{c}$ & $45,4 a$ & $15,2 \mathrm{a}$ & $95 \mathrm{a}$ & $8,0 \mathrm{a}$ & $21 \mathrm{a}$ \\
\hline BGF12770 & I & $18,0 \mathrm{a}$ & $51,3 \mathrm{a}$ & $12,8 b$ & $95 \mathrm{a}$ & $2,0 \mathrm{~b}$ & $25 a$ \\
\hline BGF12723 & I & $10,0 \mathrm{c}$ & $52,1 \mathrm{a}$ & $17,3 \mathrm{a}$ & $92 \mathrm{~b}$ & $5,0 \mathrm{a}$ & $8 b$ \\
\hline BGF12881 & II & $9,0 \mathrm{c}$ & $42,1 \mathrm{a}$ & $15,0 \mathrm{a}$ & $90 \mathrm{~b}$ & $5,0 \mathrm{a}$ & $20 \mathrm{a}$ \\
\hline BGF12905 & II & $13,0 \mathrm{~b}$ & $41,3 a$ & $19,2 \mathrm{a}$ & $95 \mathrm{a}$ & $4,0 \mathrm{~b}$ & $5 b$ \\
\hline BGF12816 & II & $12,0 \mathrm{C}$ & $35,6 \mathrm{a}$ & $12,1 \mathrm{~b}$ & $83 d$ & $5,0 \mathrm{a}$ & $8 \mathrm{~b}$ \\
\hline BGF12780 & III & $8,0 \mathrm{c}$ & $45,0 \mathrm{a}$ & $17,3 \mathrm{a}$ & $95 \mathrm{a}$ & $5,0 \mathrm{a}$ & $25 \mathrm{a}$ \\
\hline BGF12934 & III & $16,0 \mathrm{a}$ & $39,4 \mathrm{a}$ & $8,0 \mathrm{~b}$ & $92 \mathrm{~b}$ & $3,0 \mathrm{~b}$ & $20 \mathrm{a}$ \\
\hline BGF16046 & III & $11,0 \mathrm{c}$ & $29,7 \mathrm{a}$ & $9,3 \mathrm{~b}$ & $81 d$ & $5,0 \mathrm{a}$ & $10 \mathrm{~b}$ \\
\hline BGF16024 & III & $8,0 \mathrm{c}$ & $38,1 \mathrm{a}$ & $11,2 \mathrm{~b}$ & $92 \mathrm{~b}$ & $6,0 \mathrm{a}$ & $21 \mathrm{a}$ \\
\hline BGF12863 & IV & $10 \mathrm{c}$ & $37,1 \mathrm{a}$ & $10,5 b$ & $82 d$ & $8,0 \mathrm{a}$ & $12 b$ \\
\hline BGF16037 & IV & $10 \mathrm{c}$ & $42,43 \mathrm{a}$ & $14,2 \mathrm{a}$ & $87 c$ & $7,0 \mathrm{a}$ & $10 \mathrm{~b}$ \\
\hline BGF16057 & $\mathrm{V}$ & $12 \mathrm{c}$ & $33,9 \mathrm{a}$ & $9,2 \mathrm{~b}$ & $80 \mathrm{~d}$ & $5,0 \mathrm{a}$ & $8 b$ \\
\hline BGF12871 & V & $13 b$ & $43,3 \mathrm{a}$ & $15,0 \mathrm{a}$ & $92 \mathrm{~b}$ & $4,0 \mathrm{~b}$ & $11 \mathrm{~b}$ \\
\hline BGF16004 & $\mathrm{VI}$ & $9 c$ & $39,9 \mathrm{a}$ & $10,1 \mathrm{~b}$ & $92 \mathrm{~b}$ & $5,0 \mathrm{a}$ & $18 \mathrm{a}$ \\
\hline BGF16020 & VI & $8,0 \mathrm{c}$ & $39,4 \mathrm{a}$ & $12,4 \mathrm{~b}$ & $92 \mathrm{~b}$ & $6,0 \mathrm{a}$ & $19 a$ \\
\hline BGF12895 & VII & $8,0 \mathrm{c}$ & $41,3 \mathrm{a}$ & $18,8 \mathrm{a}$ & $90 \mathrm{~b}$ & $6,0 \mathrm{a}$ & $19 \mathrm{a}$ \\
\hline BGF12801 & VII & $8,0 \mathrm{c}$ & $44,6 \mathrm{a}$ & $7,3 \mathrm{~b}$ & $95 \mathrm{a}$ & $6,0 \mathrm{a}$ & $32 \mathrm{a}$ \\
\hline BGF12810 & VIII & $16,0 \mathrm{a}$ & $41,0 \mathrm{a}$ & $11,5 b$ & $92 \mathrm{~b}$ & $2,0 \mathrm{~b}$ & $17 \mathrm{a}$ \\
\hline BGF12753 & VIX & $14,0 \mathrm{~b}$ & $45,2 \mathrm{a}$ & $8,2 \mathrm{~b}$ & $90 \mathrm{~b}$ & $3,0 \mathrm{~b}$ & $24 a$ \\
\hline
\end{tabular}

${ }^{1}$ Análise de variância. *Significativo pelo teste $\mathrm{F}$ (valor de $\left.\mathrm{p}<0,05\right)$.

${ }^{2}$ Teste de comparação de médias. Médias seguidas pela mesma letra na coluna pertencem ao mesmo agrupamento pelo teste de Scott-Knott (valor de $p>0,05$ ).

${ }^{3} \mathrm{DPE}=$ dias para emergência, $\mathrm{AT}=$ altura total, $\mathrm{Al}=$ altura de inserção da primeira vagem, $\mathrm{DC}=$ dias para colheita, $\mathrm{EF}=\mathrm{estande}$ final, NVP = número de vagem/planta.

Entre as variáveis, cabe ainda ressaltar a característica massa de 100 sementes. Os acessos foram 
discriminados em dois grupos fornecendo indicativos de genótipos de centros de origem diferentes. Genótipos pertencentes ao grupo mesoamericano possuem massa de 100 sementes inferior a $25 \mathrm{~g}$, enquanto os pertencentes ao grupo andino apresentam massa de 100 sementes superior a $30 \mathrm{~g}$ (GEPTS \& BLISS 1986). O grupo formado por valores maiores apresentou o valor médio de massa de 100 sementes de $31,5 \mathrm{~g}$, constituído dos acessos BGF 12863, 16037, 12816, 16057, 12871, 12905, 12810, 12723 e 16046, indicando que $45 \%$ dos genótipos avaliados seriam pertencentes ao grupo gênico andino. Já os acessos BGF 16004, 12881, 12791, 12801, 16020, 12780, 12934, 12770, 12895, 12753 e 16024, resultaram em um valor médio de $15,99 \mathrm{~g}$, demonstrando diferença entre grupos bem notória. Já para a altura total da planta, o teste de comparação de médias não separou os acessos em mais de um grupo.

Tabela 3. Análise de variância das características, distribuição dos acessos de feijão comum em diferentes grupos de dissimilaridade estabelecidos pelo agrupamento de Tocher e média das características avaliadas para os 20 acessos de feijão.

Table 3. Analysis of variance of the characteristics, distribution of common bean accessions in different dissimilarity groups established by Tocher grouping and mean values of the evaluated characteristics for the 20 bean accessions.

\begin{tabular}{lllllll}
\hline${ }^{1}$ FV & ${ }^{3} \mathrm{CV}$ & ${ }^{3}$ REND & ${ }^{3}$ M100 & ${ }^{3} \mathrm{CS}$ & ${ }^{3} \mathrm{LS}$ & ${ }^{3} \mathrm{ES}$ \\
\hline Trat & $4,68^{*}$ & 2279419,61 & 210,75 & 11,35 & 1,13 & 1,86 \\
Erro & 0,44 & 482513,99 & 33,20 & 0,12 & 0,04 & 0,05 \\
\hline${ }^{2}$ BGF12791 & $9,3 \mathrm{c}$ & $3074,0 \mathrm{a}$ & $18,0 \mathrm{~b}$ & $9,0 \mathrm{f}$ & $6,1 \mathrm{~d}$ & $4,3 \mathrm{c}$ \\
BGF12770 & $10,3 \mathrm{c}$ & $1124,4 \mathrm{~b}$ & $13,1 \mathrm{~b}$ & $8,4 \mathrm{~g}$ & $5,7 \mathrm{e}$ & $3,9 \mathrm{~d}$ \\
BGF12723 & $12,1 \mathrm{a}$ & $1525,7 \mathrm{~b}$ & $31,3 \mathrm{a}$ & $14,4 \mathrm{a}$ & $7,7 \mathrm{a}$ & $5,4 \mathrm{~b}$ \\
\hline BGF12881 & $9,9 \mathrm{c}$ & $1391,9 \mathrm{~b}$ & $13,9 \mathrm{~b}$ & $9,4 \mathrm{f}$ & $6,0 \mathrm{~d}$ & $3,5 \mathrm{e}$ \\
BGF12905 & $10,7 \mathrm{c}$ & $612,1 \mathrm{~b}$ & $32,5 \mathrm{a}$ & $12,3 \mathrm{c}$ & $7,2 \mathrm{~b}$ & $5,6 \mathrm{a}$ \\
BGF12816 & $10,2 \mathrm{c}$ & $1086,8 \mathrm{~b}$ & $29,3 \mathrm{a}$ & $10,4 \mathrm{e}$ & $7,0 \mathrm{~b}$ & $5,6 \mathrm{a}$ \\
\hline BGF12780 & $9,9 \mathrm{c}$ & $2389,2 \mathrm{a}$ & $16,8 \mathrm{~b}$ & $9,7 \mathrm{e}$ & $6,2 \mathrm{~d}$ & $3,9 \mathrm{~d}$ \\
BGF12934 & $10,3 \mathrm{c}$ & $595,7 \mathrm{~b}$ & $14,4 \mathrm{~b}$ & $10,1 \mathrm{e}$ & $6,2 \mathrm{~d}$ & $3,7 \mathrm{~d}$ \\
BGF16046 & $12,5 \mathrm{a}$ & $1565,1 \mathrm{~b}$ & $33,9 \mathrm{a}$ & $13,5 \mathrm{~b}$ & $7,2 \mathrm{~b}$ & $5,2 \mathrm{~b}$ \\
BGF16024 & $9,7 \mathrm{c}$ & $1497,1 \mathrm{~b}$ & $14,7 \mathrm{~b}$ & $9,6 \mathrm{f}$ & $6,2 \mathrm{~d}$ & $3,7 \mathrm{~d}$ \\
\hline BGF12863 & $12,1 \mathrm{a}$ & $2715,6 \mathrm{a}$ & $32,1 \mathrm{a}$ & $13,4 \mathrm{~b}$ & $7,1 \mathrm{~b}$ & $4,6 \mathrm{c}$ \\
BGF16037 & $12,7 \mathrm{a}$ & $2169,4 \mathrm{a}$ & $31,4 \mathrm{a}$ & $13,1 \mathrm{~b}$ & $6,6 \mathrm{c}$ & $5,0 \mathrm{~b}$ \\
\hline BGF16057 & $11,4 \mathrm{~b}$ & $1235,0 \mathrm{~b}$ & $31,4 \mathrm{a}$ & $12,0 \mathrm{~d}$ & $7,0 \mathrm{~b}$ & $5,4 \mathrm{~b}$ \\
BGF12871 & $11,2 \mathrm{~b}$ & $1221,4 \mathrm{~b}$ & $26,9 \mathrm{a}$ & $12,6 \mathrm{c}$ & $7,0 \mathrm{~b}$ & $5,3 \mathrm{~b}$ \\
\hline BGF16004 & $10,3 \mathrm{c}$ & $2157,4 \mathrm{a}$ & $18,4 \mathrm{~b}$ & $9,6 \mathrm{f}$ & $6,1 \mathrm{~d}$ & $4,3 \mathrm{c}$ \\
BGF16020 & $7,8 \mathrm{~d}$ & $1551,6 \mathrm{~b}$ & $14,3 \mathrm{~b}$ & $7,6 \mathrm{~h}$ & $6,0 \mathrm{~d}$ & $4,5 \mathrm{c}$ \\
\hline BGF12895 & $9,5 \mathrm{c}$ & $517,6 \mathrm{~b}$ & $12,4 \mathrm{~b}$ & $9,2 \mathrm{f}$ & $6,1 \mathrm{~d}$ & $3,4 \mathrm{e}$ \\
BGF12801 & $10,9 \mathrm{~b}$ & $3757,8 \mathrm{a}$ & $16,8 \mathrm{~b}$ & $9,2 \mathrm{f}$ & $5,8 \mathrm{e}$ & $4,3 \mathrm{c}$ \\
\hline BGF12810 & $10,3 \mathrm{c}$ & $595,9 \mathrm{~b}$ & $35,0 \mathrm{a}$ & $11,7 \mathrm{~d}$ & $7,6 \mathrm{a}$ & $5,9 \mathrm{a}$ \\
\hline BGF12753 & $8,7 \mathrm{~d}$ & $1265,7 \mathrm{~b}$ & $23,1 \mathrm{~b}$ & $9,9 \mathrm{e}$ & $6,6 \mathrm{c}$ & $4,3 \mathrm{c}$ \\
\hline
\end{tabular}

${ }^{1}$ Análise de variância. *Significativo pelo teste $\mathrm{F}$ (valor de $\left.\mathrm{p}<0,05\right)$.

${ }^{2}$ Teste de comparação de médias. Médias seguidas pela mesma letra na coluna pertencem ao mesmo agrupamento pelo teste de Scott-Knott (valor de $p>0,05)$.

${ }^{3} \mathrm{CV}=$ comprimento da vagem, REND = rendimento de grãos, M100 = massa de 100 sementes, CS =comprimento da semente, LS = largura da semente, ES = espessura da semente.

Ao verificar a contribuição relativa de cada variável na Tabela 4, é possível observar que os aspectos morfológicos da semente são responsáveis por $74,37 \%$ da divergência total. O comprimento da semente que apresentou a maior variação $(45,54 \%)$, contribuindo consideravelmente para discriminação dos genótipos, foi a característica onde houve maior número de grupos pelo teste de Scott-Knott (análise univariada). Estudo realizado por CABRAL et al. (2011) em feijão comum, também constatou que as características morfológicas das sementes estão entre as principais variáveis que contribuem relativamente para a divergência genética. Da mesma forma, os autores verificaram que as variáveis que agruparam os Rev. Ciênc. Agrovet., Lages, SC, Brasil (ISSN 2238-1171) 
acessos em apenas dois grupos pela comparação de médias, obtiveram menor importância na discriminação dos acessos (Al, EF, NVP, REND). Esse fato demonstra que tais variáveis não são as mais relevantes em estudos de divergência genética ou duplicidade de genótipos em bancos de germoplasma, embora sejam importantes de serem avaliadas para que se conheça o potencial produtivo do genótipo. A menor amplitude de variação encontrada para essas características pode estar relacionada com a forte influência ambiental que as mesmas apresentam. O fato relevante no trabalho citado acima é a compatibilidade entre as análises univariada e multivariada, para a discriminação dos genótipos. Trabalhos realizados por BENIN et al. (2003) com a cultura da aveia, ABREU et al. (2004) com acessos de feijão de vagem, SHIMOYA et al. (2002) em acessos de capim elefante e BAHIA et al. (2008) em cultivares de mamoeira, utilizaram técnicas univariada e multivariada para verificar a divergência entre genótipos. A relação existente entre as análises poderia auxiliar na melhor discriminação dos genótipos, melhorando a eficiência da seleção ou hibridação.

Tabela 4. Contribuição relativa das 12 características avaliadas nos acessos de feijão comum, por meio da metodologia de SINGH (1981) e quantidade de grupos formados por característica pelo teste de Scott-Knott.

Table 4. Relative contribution of 12 evaluated characteristics in common bean accesses, using Singh's methodology (1981) and number of groups formed by characteristic by Scott-Knott's test.

\begin{tabular}{lccc}
\hline Variável & Contribuição relativa em \% & Scott-Knott & Valor acumulado (\%) \\
\hline CS & 46,54 & 8 & 46,54 \\
ES & 21,96 & 5 & 68,50 \\
LS & 5,87 & 5 & 74,37 \\
DC & 5,48 & 4 & 79,85 \\
CV & 5,11 & 4 & 84,96 \\
M100 & 3,12 & 2 & 88,08 \\
DPE & 2,66 & 3 & 90,74 \\
AI & 2,27 & 2 & 93,01 \\
REND & 2,16 & 2 & 95,17 \\
NLP & 1,71 & 2 & 96,88 \\
AT & 1,70 & 0 & 98,58 \\
EF & 1,42 & 2 & 100,00 \\
\hline
\end{tabular}

$\overline{C S}=$ comprimento da semente, $\mathrm{ES}=$ espessura da semente, $\mathrm{LS}=$ largura da semente, $\mathrm{DC}=$ dias para colheita, $\mathrm{CV}=$ comprimento da vagem, $\mathrm{M} 100$ = massa de 100 sementes, $\mathrm{DPE}=$ dias para emergência, $\mathrm{Al}=$ altura de inserção da primeira vagem, $\mathrm{REND}=$ rendimento de grãos, NVP = número de vagem por plant, $A T$ = altura total, $E F=$ estande final.

Após a constatação da variabilidade genética para cada característica individual, realizou-se o diagnóstico de multicolinearidade. O diagnóstico de multicolinearidade apresentou número de condição (NC) igual a 15,4621, indicando colinearidade fraca segundo o critério de MONTGOMERY et al. (1981) não constituindo problema sério na estimação dos parâmetro posteriores. Além disso, o descarte de variáveis que causem a multicolinearidade pode ocasionar a exclusão de variáveis importantes em um programa de melhoramento. Assim, a distância generalizada de Mahalanobis considera a existência de correlações entre os caracteres analisados por meio da matriz de variâncias e covariâncias residuais (CRUZ \& REGAZZI 1994, CRUZ et al. 2004). O método de SINGH (1981), baseado na técnica multivariada de quantificação da distância de Mahalanobis $\left(D^{2}\right)$, permite inferir sobre a importância relativa de cada característica para a dissimilaridade genética. O maior ganho na avaliação da importância relativa dos caracteres consiste em verificar quais características tem a menor contribuição, consequentemente menor discriminação dos genótipos avaliados (ALVES et al. 2003, ROTILI et al. 2012). Com isso, essas características que são pouco representativas, podem ser descartadas reduzindo assim a mão-de-obra, tempo e custos destinados ao experimento.

O método de agrupamento por otimização ou método de Tocher, apresentado em CRUZ et al. (2014), constitui um método de agrupamento simultâneo, o qual realiza a separação dos genótipos em grupos de uma só vez. Esse método requer a obtenção da matriz de dissimilaridade, sobre o qual será identificado o par de indivíduos mais similares. O método de Tocher é amplamente empregado no estudo da divergência genética entre acessos. SOUZA et al. (2005) avaliaram a divergência genética entre 31 
genótipos de melancia, por meio de técnicas de agrupamento e de variáveis canônicas. OLIVEIRA et al. (2004) também utilizou o método de Tocher na avaliação de divergência genética entre genótipos de alface. SILVA et al. (2005) utilizaram esse método a fim de avaliar a diversidade genética de genótipos de cana-deaçúcar. MARCHIORO et al. (2003) utilizaram o método de agrupamento de Tocher para avaliação da dissimilaridade genética entre genótipos de aveia. Em tomateiro, KARASAWA et al. (2005) usaram esse método para avaliar a divergência genética entre acessos de bancos de germoplasma, permitindo indicação de genitores potenciais para a utilização em programas de melhoramento.

A análise de agrupamento utilizando o método de Tocher possibilitou a distribuição dos 20 acessos de feijão em nove grupos, alocando os genótipos mais divergentes em grupos diferentes (Tabelas 2 e 3 ). $O$ grupo I, formado pelos acessos BGF 12791, 12770 e 12723 representam o grupo que tiveram plantas mais altas (média de 49,6 cm) e uma das maiores médias da inserção da primeira vagem, características importantes quando se almeja obter genótipos de feijão para colheita mecanizada. Além disso, o grupo I apresentou plantas com ciclo mais longo (94 dias). O grupo III é responsável pelas plantas de menor porte $(38,05 \mathrm{~cm})$. O grupo IV, o qual alocou maior quantidade de acessos (BGF 12780, 16046, 16024, 12934) destaca-se pelo maior rendimento de grãos, apresentando uma média de $2442,0 \mathrm{~kg} \mathrm{ha}^{-1}$, quase o dobro do rendimento médio nacional de $1268 \mathrm{~kg} \mathrm{ha}^{-1}$ estimado para a cultura na primeira safra de feijão de 2016/17 (CONAB 2017). O grupo VI alocou os acessos que tiveram suas plântulas emergidas em menos dias, contudo esse fator não fez com que o grupo fosse o mais precoce em relação ao seu ciclo. Também foram os acessos que resultaram em menores médias referente ao comprimento e largura da semente. $O$ grupo VIII e VIX foram formados apenas por um acesso cada, sendo as principais características, o menor rendimento de grãos e menor altura de inserção da primeira vagem, respectivamente.

O acesso BGF 12810 (grupo VIII) e o BGF 12753 (grupo VIX) ficaram em grupos isolados, provando serem os acessos mais divergentes visto que não se assemelharam a nenhum outro. Diferentemente, no teste de Scott-Knott, levando em consideração a característica que mais ocorreu variação (comprimento da semente), o BGF 12753 ficou agrupado com mais três acessos (BGF 12816, BGF 12780, BGF 12934). O BGF 12810, referindo-se a mesma característica, ficou em um grupo com o acesso BGF 16057. Ou seja, quando avaliada unicamente essa característica, os acessos BGF 12810 e BGF 12753 são semelhantes a outros genótipos. Entretanto, levando em consideração outras variáveis e a correlação entre elas, os acessos BGF 12810 e BGF 12753 tornam-se discrepantes em relação aos outros. Em trabalho realizado por VOGT et al. (2010) com girassol, o teste de comparação de médias de Scott- Knott levou a formação de até cinco grupos dentre as características, enquanto o agrupamento de Tocher alocou as cultivares em apenas três grupos distintos. Da mesma forma, SILVA et al. (2014) utilizando o teste de Scott-Knott, segregou os acessos de cajazinho em até cinco grupos e o agrupamento de Tocher distinguiu apenas três grupos. Resultado diferente foi encontrado por SANTOS et al. (2011) estudando genótipos de soja cultivados em várzeas, onde o agrupamento de Tocher agrupou 48 genótipos em apenas dois grupos, e quando realizada a análise univariada pode-se discriminar os genótipos em até nove grupos diferentes.

Analisando as demais características, chama a atenção a relação que o BGF 12770, pertencente ao grupo I pelo método de agrupamento de Tocher, tem com os dois acessos que compõem o grupo VIII (BGF 12810) e o grupo VIX (BGF 12753). No teste de Scott-Knott, o BGF 12770 não diferiu significativamente em relação a seis características com o BGF 12753 (AT, Al, NLP, REND, M100), estando assim no mesmo grupo. Da mesma maneira, ocorreu semelhança em sete características para o acesso BGF 12810 (DPE, AT, AI, EF, NLP, CL, REND) em relação com o BGF12770, ou seja, quando levou-se em consideração as características de forma independente esses genótipos se assemelham no mínimo em metade dessas variáveis. Já quando a análise leva em consideração a correlação entre as características, os genótipos são alocados em grupos distintos, identificando que são divergentes. COELHO et al. (2007) trabalhando com 20 acessos do banco germoplasma de feijão, observaram que a análise univariada demonstrou não significância para alguns caracteres e quando utilizado o método multivariado, a importância relativa das características alterou devido a sua análise correlacionada das características.

Em programas de melhoramento genético de importantes culturas, é fato comum utilizar ambas as análises, univariada e multivariada, sem estabelecer uma conexão crítica entre elas. Sem dúvida, durante muitos anos, os programas de melhoramento genético clássico se basearam nos métodos univariados para a determinação da divergência entre os genótipos. Atualmente, as análises multivariadas vêm sendo rotineiramente utilizadas (juntamente com as univariadas) em virtude da melhoria dos programas genéticoestatísticos, que trazem versões bastante simples de serem utilizadas, a exemplo do programa Genes (CRUZ 2001). Contudo, é importante frisar que quando viável, o uso de ambas deve ser aproveitado no sentido de obter maiores informações sobre os genótipos utilizados. 
No presente trabalho, foi possível estabelecer relação entre as análises univariada e multivariada sob alguns pontos de vista. Em contrapartida, sob outros, não houve relação, e a análise conjunta de ambas levanta dúvidas quanto à superioridade de uma em relação à outra. Para a utilização dos acessos avaliados, a análise multivariada seria a melhor forma de discriminar os acessos, já que o propósito da avaliação dos mesmos não tem o enfoque em nenhuma característica em especial.

\section{CONCLUSÃO}

A dissimilaridade entre os acessos de feijão comum apresentou diferenças conforme a utilização da análise univariada e multivariada. A escolha do método mais adequado para inferências sobre os dados é relativa de acordo com o objetivo que se almeja.

Para realização de um screening inicial de uma ampla gama de acessos em programas de melhoramento recomenda-se a análise multivariada.

A análise univariada é válida quando a seleção será com base em uma característica específica com conhecimento da sua contribuição relativa para divergência.

\section{REFERÊNCIAS}

ABREU FB et al. 2004. Divergência genética entre acessos de feijão-de-vagem de hábito de crescimento indeterminado. Horticultura Brasileira 22: 547-552.

ALVES RM et al. 2003. Seleção de descritores botânico-agronômicos para caracterização de germoplasma de cupuaçuzeiro. Pesquisa Agropecuária Brasileira 38: 807-818.

BAHIA HF et al. 2008. Divergência genética entre cinco cultivares de mamoneira. Pesquisa Agropecuária Brasileira 43: 357-362.

BANZATTO DA \& KRONKA SN. 2006. Experimentação agrícola. 4.ed. Jaboticabal: FUNEP. 237p.

BENIN G et al. 2003. Comparações entre medidas de dissimilaridade e estatísticas multivariadas como critérios no direcionamento de hibridações em aveia. Ciência Rural 33: 657-662.

BORGES LC \& FERREIRA DF. 2003. Poder e taxas de erro tipo I dos testes Scott-Knott, Tukey e Student-NewmanKeuls sob distribuições normais e não normais dos resíduos. Revista de Matemática e Estatística 21: 67-83.

CABRAL PDS et al. 2011. Diversidade genética de acessos de feijão comum por caracteres agronômicos. Revista de Ciência Agronômica 42: 898-905.

CARGNELUTTI FILHO A et al. 2008. Tamanho de amostra de caracteres de cultivares de feijão. Ciência Rural 38: 635642.

CATAPATTI TR et al. 2008. Tamanho de amostra e número de repetições para avaliação de caracteres agronômicos em milho-pipoca. Ciência e Agrotecnologia 32: 855-862.

CHIORATO AF. 2004. Divergência genética em acessos de feijoeiro (Phaseolus vulgaris L.) do banco de germoplasma do Instituo Agronômico-IAC. Dissertação (Mestrado em Melhoramento Vegetal). Campinas: Instituto Agronômico. 85p.

COELHO CMM et al. 2007. Diversidade genética em acessos de feijão (Phaseolus vulgaris L.). Revista Ciência Rural 35: 1241-1247.

COIMBRA JLM et al. 2007. Técnicas multivariadas aplicadas ao estudo da fauna do solo: contrastes multivariados e análise canônica discriminante. Revista Ceres 54: 270-276.

CONAB. 2017. Companhia Nacional de Abastecimento. Acompanhamento da safra brasileira de grãos: quinto levantamento safra 2016/2017. Brasília: CONAB. 166p.

CRUZ CD et al. 1994. Estudos sobre a divergência genética. II. Eficiência da predição do comportamento de híbridos com base na divergência genética de progenitores. Revista Ceres 41: 183-190.

CRUZ CD et al. 2012. Modelos biométricos aplicados ao melhoramento genético. 4.ed. Viçosa: UFV. 508p.

CRUZ CD. 2001. Programa Genes - Versão Windows: aplicativo computacional em genética e estatística. Viçosa: UFV. 648 .

CRUZ CD et al. 2004. Modelos biométricos aplicados ao melhoramento genético. 3.ed. Viçosa: UFV. 480p.

CRUZ CD \& REGAZZI AJ 1994. Modelos biométricos aplicados ao melhoramento genético. 1.ed. Viçosa: UFV. 390p.

CRUZ CD et al. 2014. Modelos biométricos aplicados ao melhoramento genético. 3. ed. rev. Viçosa: UFV 668p.

DALLASTRA A et al. 2014. Multivariate approach in the selection of superior soybean progeny which carry the RR gene. Revista Ciência Agronômica 45: 588-597.

RANGEL PHN et al. 2013. Banco ativo de germoplasma de arroz e feijão: passado, presente e futuro. Santo Antônio de Goiás, Embrapa Arroz e Feijão. 60p. (Documentos 288).

GEPTS P \& BLISS FA. 1986. Phaseolin variablity among wild and cultivated common beans (Phaseolus vulgaris) from Colombia. Economic Botany 40: 469-478.

GONÇALVES DL et al. 2014. Divergência genética de acessos tradicionais de feijoeiros através de características das sementes. Biosciense Journal 30: 1671-1681.

JADOSKI SO et al. 2000. População de plantas e espaçamento entre linhas do feijoeiro irrigado. I: Comportamento morfológico das plantas. Revista Ciência Rural 30: 559-565.

KARASAWA $M$ et al. 2005. Aplicação de métodos de agrupamento na quantificação da divergência genética entre acessos de tomateiro. Horticultura Brasileira 23: 1000-1005. 
KRAUSE W et al. 2012. Capacidade combinatória para características agronômicas em feijão-de-vagem. Revista Ciência Agronômica 43: 522-531.

LIMA MS et al. 2012. Characterization of genetic variability among common bean genotypes by morphological descriptors. Crop Breeding and Applied Biotecnology 12: 76-84.

MARCHIORO VS et al. 2003. Dissimilaridade genética entre genótipos de aveia. Ciência e Agrotecnologia 27: $285-294$.

MONTGOMERY DC et al.1981. Introduction to linear regression analysis. New York: John Wiley \& Sons. 504p.

OLIVEIRA ACB et al. 2004. Divergência genética e descarte de variáveis em alface cultivada sob sistema hidropônico. Acta Scientiarum Agronomy 26: 211-217.

RAMALHO MAP et al. 2005. A experimentação em genética e melhoramento de plantas. 2.ed. Lavras: UFLA. 300p.

RAO RC. 1952. Advanced statistical methods in biometric research. New York: John Wiley \& Sons. 390p.

RIBEIRO NF et al. 2001. Bordadura em ensaios de competição de genótipos de feijoeiro relacionados à precisão experimental. Ciência Rural 31: 13-17.

ROTILI EA et al. 2012. Divergência genética em genótipos de milho, no Estado de Tocantins. Revista Ciência Agronômica 43: 516-521.

SALGADO FHM et al. 2011. Comportamento de genótipos de feijão, no período da entressafra, no Sul do Estado de Tocantins. Biosciense Journal 27: 52-58.

SANTOS ER et al. 2011. Divergência entre genótipos de soja, cultivados em várzea irrigada. Revista Ceres 58: $755-764$. SCOTT AJ \& KNOTT M. 1974. Cluster analysis method for grouping means in the analysis of variance. Biometrics 30 : 507-512.

SHIMOYA A et al. 2002. Divergência genética entre acessos de um banco de germoplasma de capimelefante. Pesquisa Agropecuária Brasileira 37: 971-980.

SILVA CA et al. 2014. Divergência genética entre acessos de cajazinho (Spondias mombin L.) no norte do Espírito Santo. Revista Ceres 61: 362-369.

SILVA CM et al. 2005. Genetic diversity among sugarcane clones (Saccharum spp.). Acta Scientiarum Agronomy 27: 315-319.

SILVA HT. 2005. Descritores mínimos indicados para caracterizar cultivares/variedades de feijão comum (Phaseolus vulgairs L.). Santo Antônio de Goiás: Embrapa Arroz e Feijão. 32p.

SILVA JG \& FONSECA JR. 1996. Colheita. In: ARAUJO RS et al. Cultura do feijoeiro comum no Brasil. Piracicaba: Potafos. p.523-541.

SILVA JGC \& MACHADO AA. 2001. Análise Multivariada: extensões de métodos univariados. 1.ed. Pelotas: Instituto de Física e Matemática UFP. 256p.

SILVEIRA GM. 1991. As máquinas para colheita e transporte. São Paulo: Globo. 183p.

SINGH D. 1981. The relative importance of characters affecting genetic divergence. Indian Journal of Genetics and Plant Breeding 41: 237-245.

SOCIEDADE BRASILEIRA DE CIÊNCIA DO SOLO. 2004. Manual de adubação e de calagem para os Estados do Rio Grande do Sul e Santa Catarina. 10.ed. Porto Alegre: Núcleo Regional Sul. Comissão de Química e Fertilidade do Solo. 400p.

SOUZA FF et al. 2005. Divergência genética em linhagens de melancia. Horticultura Brasileira 23: 179-183.

TSUTSUMI CY et al. 2015. Melhoramento genético do feijoeiro: avanços, perspectivas e novos estudos, no âmbito nacional. Revista Nativa 3: 217-223.

VALLS JFM. 2007. Caracterização de recursos genéticos vegetais. In: NASS LL. (Ed.) Recursos genéticos vegetais. Brasília: Embrapa Recursos genéticos e Biotecnologia. p.281-305.

VOGT GA et al. 2010. Divergência genética entre cultivares de girassol no planalto norte catarinense. Scientia Agraria 11: 307-315. 